\title{
Erythrocyte incorporation of iron by infants: iron bioavailability from a low-iron infant formula and an evaluation of the usefulness of correcting erythrocyte incorporation values, using a reference dose or plasma ferritin concentrations
}

\author{
Lena Davidsson $^{1} *$, Ekhard E. Ziegler ${ }^{2}$, Peter Kastenmayer ${ }^{1}$, and Richard F. Hurrell ${ }^{1}$ \\ ${ }^{1}$ Nestlé Research Center Lausanne, PO Box 44, 1000 Lausanne 26, Switzerland \\ ${ }^{2}$ Department of Pediatrics, University of Iowa, Iowa City, IA 52242, USA \\ (Received 20 September 1999 - Revised 3 April 2000 - Accepted 20 July 2000)
}

\begin{abstract}
Bioavailability of iron ( $\mathrm{Fe}$ ) from a low-Fe infant formula was determined by erythrocyte incorporation of ${ }^{58} \mathrm{Fe} 14 \mathrm{~d}$ after administration in ten healthy, non-Fe-deficient infants. Two feeding protocols were compared, with each infant acting as his/her own control. At 140 and $154 \mathrm{~d}$ of age, infants were fed $1000 \mathrm{~g}$ of ${ }^{58} \mathrm{Fe}$-labelled formula (1.44 mg total Fe/1000 g) as six feeds over $24 \mathrm{~h}$ (Protocol A) or as two feeds/day on three consecutive days (Protocol B). A water solution with ${ }^{57} \mathrm{Fe}$ and ascorbic acid was given separately as a reference dose in both study protocols. Erythrocyte incorporation of ${ }^{58} \mathrm{Fe}$ and ${ }^{57} \mathrm{Fe}$ was determined by thermal ionisation mass spectrometry. Geometric mean ${ }^{58} \mathrm{Fe}$ incorporation was $7.6 \%$ (range $3.3-13.5 \%$ ) with Protocol A as compared to $10.6 \%$ (range 6.7-18.6\%) with Protocol B $(P=0.05)$; paired $t$ test. Inter-individual variability of ${ }^{58} \mathrm{Fe}$ was not reduced by correcting for the incorporation of ${ }^{57} \mathrm{Fe}$ from the reference dose, or by correcting for plasma ferritin concentration. Fractional erythrocyte incorporation of Fe from low-Fe infant formula was in the same range as our earlier published data on erythrocyte incorporation of Fe from human milk extrinsically labelled with ${ }^{58} \mathrm{Fe}$ (Davidsson et al. 1994a). The methodological evaluations included in this study clearly indicate the importance of using standardised study protocols when evaluating $\mathrm{Fe}$ bioavailability in infants. Corrections of erythrocyte incorporation data based on plasma ferritin or erythrocyte incorporation of Fe from a reference dose were not found to be useful.
\end{abstract}

Iron: Infants: Infant formula: Stable isotopes

Iron (Fe) deficiency is a major public health problem during early life, in particular in developing countries but also in infants and young children in industrialised countries (Innis et al. 1997, Looker et al. 1997). At birth, healthy term infants are endowed with substantial amounts of Fe, predominantly in haemoglobin, but also as tissue and storage Fe (Dallman, 1992). During the first months of life, body $\mathrm{Fe}$ present at birth, together with absorbed dietary $\mathrm{Fe}$, are used to support the rapid expansion of the red blood cell mass as the infant grows. Dietary intake of Fe during the first months of life varies considerably, depending on feeding practices. Exclusive breast-feeding is strongly recommended during the first 4-6 months of life for infants in both developing and developed countries; however, human milk contains little Fe (Siimes et al.
1979, Lönnerdal, 1984). Depending on socio-economic factors, availability and local feeding practices, infants who are not breast-fed, or are partially breast-fed, are fed infant formulas either industrially produced or home made. Most commercial infant formulas are fortified with $\mathrm{Fe}$, although $\mathrm{Fe}$ concentrations vary widely between countries. For example, Fe concentration in European infant formulas are typically in the range 4 to $7 \mathrm{mg} / \mathrm{l}$ while in the USA Fefortified infant formulas contain about $12 \mathrm{mg} \mathrm{Fe} / \mathrm{l}$. In addition, although $\mathrm{Fe}$-fortified infant formulas are recommended by the US Academy of Pediatrics, commercial infant formulas with low Fe concentration (about 1.1$4.5 \mathrm{mg} / \mathrm{l}$ ) are commonly used in the USA (Committee on Nutrition, American Academy of Pediatrics, 1999).

Only very limited information is available on the

\footnotetext{
* Corresponding author: Lena Davidsson, present address Laboratory for Human Nutrition, Institute of Food Science, Swiss Federal Institute of Technology, PO Box 474, CH-8803 Rüschlikon, Switzerland, fax + 41170457 10, email davidsson@ilw.agrl.ethz.ch
} 
bioavailability of Fe to infants from formulas with different Fe concentrations and no evaluation of the efficacy of low$\mathrm{Fe}$ formula to supply $\mathrm{Fe}$ to infants has been reported. Therefore, the present study was designed to investigate Fe bioavailability from low-Fe infant formula in healthy infants, using a stable isotope technique based on erythrocyte incorporation of ${ }^{58} \mathrm{Fe} 14 \mathrm{~d}$ after intake of labelled test meals. In addition, an evaluation of the mode of administration of labelled test meals on erythrocyte incorporation of ${ }^{58} \mathrm{Fe}$ was included in the study. The third objective of the study was to investigate the usefulness of correcting erythrocyte incorporation values in infants using either the erythrocyte incorporation of a separately administered reference dose of ${ }^{57} \mathrm{Fe}$, or using plasma ferritin values. In adult $\mathrm{Fe}$ absorption studies, corrections using ferritin have been found more useful in reducing the inter-individual variation in Fe bioavailability than corrections based on Fe absorption from a reference dose (Cook et al. 1991).

\section{Materials and methods}

\section{Infant formulas}

A whey-predominant infant formula with low Fe content (Study Formula) was produced especially for the study according to the specifications for a commercial infant formula (Nan ${ }^{\circledR}$, Nestlé S.A., Vevey, Switzerland) except for the Fe content. Ferrous sulphate was added to a final concentration of $1.55 \mathrm{mg} \mathrm{Fe} / \mathrm{l}$ during manufacture (Nestlé Food Company, Eau Claire, WI, USA). All other nutrients met the requirements specified by the Food and Drug Administration (1985). Vitamins and minerals were purchased separately from Fortitech Inc. (Schenectady, NY, USA) and added during manufacture according to the quantities normally added to the commercial product.

A separate batch of formula was produced for the administration of stable isotopes with identical composition as the Study Formula but without added ferrous sulphate or ascorbic acid. After addition of the ${ }^{58} \mathrm{Fe}$ label (see 'Formula labelling'), the total Fe content was $1.44 \mathrm{mg} \mathrm{Fe} / 1000 \mathrm{~g}$ formula.

Both batches of formula were produced as 'Ready-toFeed' liquid formula and filled aseptically into $960 \mathrm{ml}$ cans. The nutritional composition of both products was analysed and the microbiological safety of the formulas was ensured before release from the factory.

\section{Infants and feeding regimen}

Ten term infants (four girls, six boys) were enrolled within $4 \mathrm{~d}$ of age $112 \mathrm{~d}$. Infants were fed Fe-fortified infant formulas (12 mg Fe/l) from birth. All infants were apparently healthy, with no known diseases or disorders. From enrolment at $112 \mathrm{~d}$ until completion of the study, infants were fed (on demand) the specially prepared Study Formula with Fe content of $1.55 \mathrm{mg} \mathrm{Fe} / \mathrm{l}$. After $140 \mathrm{~d}$ of age, infants were permitted limited amounts of complementary foods such as fruit and vegetable purées. Fefortified cereals were not allowed and Fe supplements were not given during the entire study. No solids were permitted during the days when ${ }^{58} \mathrm{Fe}$-labelled infant formula was fed.

\section{Study design}

Using a crossover design, each infant was studied twice with the first study performed within $4 \mathrm{~d}$ of age $140 \mathrm{~d}$ and the second study within $4 \mathrm{~d}$ of age $154 \mathrm{~d}$. Each study consisted of the administration of a precisely known amount of ${ }^{58} \mathrm{Fe}$-sulphate in $1000 \mathrm{~g}$ infant formula which was given over approximately $24 \mathrm{~h}$ (Protocol A) or in equal portions on each of three consecutive days (Protocol B). Three hours after completing the ingestion of ${ }^{58} \mathrm{Fe}$-labelled infant formula, the infants received a small volume of an aqueous solution of ${ }^{57} \mathrm{Fe}$-sulphate containing ascorbic acid (reference dose) under standardised conditions. Five infants started with Protocol A while the other five infants started with Protocol B. The order of study protocols was assigned on an alternating basis. A total of three capillary blood samples were obtained by heel-stick using disposable blades (Tenderfoot, International Technidyne Corp., Edison, NJ, USA) and collected in heparinised Microvette tubes (CB $1000 \mathrm{~S}$, Sarstedt, Newton, NC, USA). The first sample was drawn immediately before ingestion of ${ }^{58} \mathrm{Fe}$ labelled infant formula and the second and third samples $14 \mathrm{~d}$ after the start of ${ }^{58} \mathrm{Fe}$ ingestion in Protocols $\mathrm{A}$ and $\mathrm{B}$ respectively. The first enriched blood sample (drawn on day 14) was used as the baseline value for the second part of the study. Blood samples were analysed for Fe status indices and stable isotope enrichment.

\section{Stable isotopes}

Stable isotopes of $\mathrm{Fe}$ with high enrichments of ${ }^{58} \mathrm{Fe}$ $\left(>91 \%{ }^{58} \mathrm{Fe}\right.$; Isotec, St. Quentin, France) and ${ }^{57} \mathrm{Fe}(>95 \%$ ${ }^{57} \mathrm{Fe}$; Medgenix, Ratingen, Germany) were purchased as metals and converted to ${ }^{57} \mathrm{FeSO}_{4}$ and ${ }^{58} \mathrm{FeSO}_{4}$ by dissolution in $\mathrm{H}_{2} \mathrm{SO}_{4}(0.5 \mathrm{~mol} / \mathrm{l})$ according to Kastenmayer et al. (1994). Individual portions of isotope solutions containing ${ }^{58} \mathrm{Fe}$ (approximately $1.18 \mathrm{mg}$ ) or ${ }^{57} \mathrm{Fe}$ (approximately $3.00 \mathrm{mg}$ ) were prepared by precisely weighing aliquots into acid-washed Reacti vials (Pierce, Rockford, IL, USA). The vials were purged with $\mathrm{N}_{2}$ and kept refrigerated until used. Isotopic composition of the stable isotope solutions was determined by thermal ionisation mass spectrometry (TIMS; Kastenmayer et al. 1994). The exact amount of stable isotope administered to the infants was used in the calculation of fractional Fe incorporation into erythrocytes.

\section{Formula labelling}

Labelled formula was prepared during the $24 \mathrm{~h}$ immediately preceding administration by adding the contents of one vial of ${ }^{58} \mathrm{FeSO}_{4}$ to $1000 \mathrm{~g}$ infant formula without added Fe. Ascorbic acid $(75 \mathrm{mg}$ as sodium ascorbate, Fortitech Inc.) was added at the same time. The formula was stirred gently for $24 \mathrm{~h}$ at $4^{\circ} \mathrm{C}$ to ensure equilibration between added isotope and native $\mathrm{Fe}$ according to the method described earlier (Davidsson et al. 1994a). The final $\mathrm{Fe}$ content was $1.44 \mathrm{mg} \mathrm{Fe} / 1000 \mathrm{~g}$ formula. Equal portions of 
the labelled formula (approximately $167 \mathrm{~g}$ each) were weighed into six pre-weighed feeding bottles and kept refrigerated until used.

\section{Administration of labelled formula}

In Protocol A, infants were fed the first two to three bottles of labelled formula by a research nurse at the Lora N. Thomas Metabolism Ward, Department of Pediatrics, University of Iowa, Iowa City, IA, USA. The remaining labelled formula was fed by the parents at home. Parents were instructed orally and in writing about the procedure for administration of labelled formula. The next morning the infant returned to the Metabolism Ward and, if there was still labelled formula left, it was fed. The exact quantity of labelled formula ingested was calculated by weighing feeding bottles after feeding. Pre-weighed bibs and wipes were used to quantify losses of labelled formula during and after feeding. Three hours after the last feeding of labelled formula, the reference dose of ${ }^{57} \mathrm{Fe}$ was given by a research nurse.

During protocol B, the infants were fed two bottles of labelled formula on each of three consecutive days in the Metabolism Ward. Research nurses administered all labelled formula during Protocol B. The reference dose was given $3 \mathrm{~h}$ after the consumption of the last bottle of labelled formula on day 3. Procedures were otherwise as during Protocol A.

\section{Reference dose}

To the precisely weighed content of one vial of ${ }^{57} \mathrm{FeSO}_{4}$ solution were added sodium ascorbate $(123 \mathrm{mg})$ and sucrose $(630 \mathrm{mg})$ and the volume was brought to $5 \mathrm{ml}$ with deionised water (Davidsson et al. 1994a). The solution was given directly into the mouth of the infant by using a plastic syringe. No food or fluid was given for $1 \mathrm{~h}$ after ingestion of the reference dose.

\section{Analysis}

Haemoglobin was determined using a Coulter Counter (Model M430, Coulter Electronics Inc., Hialeah, FL, USA). Plasma was separated from blood cells within $30 \mathrm{~min}$ of collection and stored at $-20^{\circ} \mathrm{C}$ until ferritin was analysed by radioimmunoassay using the Quantimune kit (catalogue no. 190-2001, Bio-Rad Laboratories, Hercules, CA, USA).

Infant formulas were analysed for Fe content by atomic absorption spectrometry (Varian Techtron, model 975, Mulgrave, Australia). Duplicate samples of freeze-dried formulas were ashed in silica Ehrlenmeyer flasks in a muffle furnace at $510^{\circ} \mathrm{C}$ for $48 \mathrm{~h}$. Ash was dissolved in concentrated $\mathrm{HCl}$ and diluted to $25 \mathrm{ml}$ with ultra-pure water. Fe was measured by the standard addition technique (Van de Casteele \& Block, 1993). A reference material; Wheat Flour 1567a (National Institute of Standards and Technology, Gaithersburg, MD, USA) was analysed together with the formulas. The analysed value (13.8 \pm $0.6 \mu \mathrm{g} / \mathrm{g}$ ) was found to be within the certified range for $\mathrm{Fe}$ $(14.1 \pm 0.5 \mu \mathrm{g} / \mathrm{g})$. The nutritional composition of the two formulas was analysed by standard techniques in a quality control laboratory (Nestlé Food Company).

Thermal ionisation mass spectrometry was used for measurements of isotopic ratios in whole blood samples according to the method described in detail earlier (Kastenmayer et al. 1994).

\section{Calculations and statistical methods}

The quantity of ${ }^{58} \mathrm{Fe}$ and ${ }^{57} \mathrm{Fe}$ incorporated into erythrocytes was calculated as previously described (Kastenmayer et al. 1994) and was expressed as a percentage of the amount administered. Correction of cross-contamination of stable isotopes was made by assuming that the contribution of ${ }^{57} \mathrm{Fe}$ from the ${ }^{58} \mathrm{Fe}$ label was negligible (Kastenmayer et al. 1994). The amount of ${ }^{58} \mathrm{Fe}$ ingested with the ${ }^{57} \mathrm{Fe}$ label, which was incorporated into erythrocytes, was then calculated, assuming an identical absorption for both isotopes present in the ${ }^{57} \mathrm{Fe}$ label. Isotopic enrichments determined 2 weeks after the first administration of isotopes served as baseline values for calculations of erythrocyte incorporation after the second isotope administration.

Values for erythrocyte incorporation of ${ }^{58} \mathrm{Fe}$ were corrected to the geometric mean incorporation of ${ }^{57} \mathrm{Fe}$ from the reference dose and to the geometric mean plasma ferritin concentration according to Cook et al. (1991), using for each subject the mean of all available plasma ferritin analyses (two to three analyses per infant).

Student's paired $t$ test was used for comparisons of erythrocyte incorporation of ${ }^{58} \mathrm{Fe}$ and ${ }^{57} \mathrm{Fe}$ between Protocols A and B. Values were converted to logarithms before statistical analysis and reconverted to antilogarithms to recover the original values (Cook et al. 1969). Order effect (Protocol A v. Protocol B) was tested by using twosample $t$ tests. Comparisons were also made by randomized block analysis of variance using ${ }^{57} \mathrm{Fe}$ incorporation from the reference dose as a covariate. Correlations between erythrocyte incorporation of ${ }^{57} \mathrm{Fe}$ from the reference doses administered on two separate occasions as well as between plasma ferritin concentrations and erythrocyte incorporation of ${ }^{58} \mathrm{Fe}$ and ${ }^{57} \mathrm{Fe}$ were evaluated by Spearman's rank correlation.

\section{Ethical considerations}

The study protocol was reviewed and approved by the University of Iowa Committee on Research Involving Human Subjects. Parents were informed about the aims and procedures of the study and informed consent was obtained from at least one parent of each infant.

\section{Results}

The Study Formula provided (per litre) $2733 \mathrm{~kJ}$, protein $1.68 \mathrm{~g}, \mathrm{Fe} 1.55 \mathrm{mg}$, zinc $6.2 \mathrm{mg}$, calcium $532 \mathrm{mg}$, phosphorus $313 \mathrm{mg}$ and ascorbic acid $109 \mathrm{mg}$. Corresponding values for the infant formula manufactured without added $\mathrm{Fe}$ or ascorbic acid were $2724 \mathrm{~kJ}$, protein $1.66 \mathrm{~g}, \mathrm{Fe}$ $0.13 \mathrm{mg}$, zinc $5.9 \mathrm{mg}$, calcium $550 \mathrm{mg}$ and phosphorus $319 \mathrm{mg}$. No ascorbic acid was detected in this product. 
Table 1. Age, sex, body weight and iron status indices (haemoglobin and plasma ferritin) of participating infants

\begin{tabular}{|c|c|c|c|c|c|}
\hline Infant & Sex & Age (d) & Body weight (g) & Haemoglobin (g/l) & Plasma-ferritin $(\mu \mathrm{g} / \mathrm{l})$ \\
\hline \multirow[t]{3}{*}{5685} & $M$ & 138 & 8580 & 140 & ND \\
\hline & & 152 & 8790 & 146 & 51 \\
\hline & & 166 & 9060 & 140 & 48 \\
\hline \multirow[t]{3}{*}{5941} & $\mathrm{M}$ & 143 & 6810 & 128 & 58 \\
\hline & & 157 & 7160 & 128 & 47 \\
\hline & & 170 & 7530 & 122 & 39 \\
\hline \multirow[t]{3}{*}{5946} & $\mathrm{~F}$ & 142 & 7150 & 116 & 55 \\
\hline & & 156 & 7210 & 122 & 42 \\
\hline & & 169 & 7870 & 112 & 46 \\
\hline \multirow[t]{3}{*}{5947} & $\mathrm{M}$ & 144 & 6790 & 111 & 27 \\
\hline & & 158 & 7020 & 116 & 20 \\
\hline & & 172 & 7200 & 116 & 30 \\
\hline \multirow[t]{3}{*}{5949} & $\mathrm{M}$ & 141 & 7820 & 122 & 84 \\
\hline & & 154 & 8070 & 124 & 57 \\
\hline & & 169 & 8230 & 126 & 50 \\
\hline \multirow[t]{3}{*}{5696} & $M$ & 136 & 7190 & 126 & 33 \\
\hline & & 150 & 7340 & 126 & 24 \\
\hline & & 164 & 7450 & 126 & 27 \\
\hline \multirow[t]{3}{*}{5272} & $\mathrm{~F}$ & 136 & 8140 & 128 & 112 \\
\hline & & 150 & 8290 & 125 & 86 \\
\hline & & 169 & 9010 & 116 & 39 \\
\hline \multirow[t]{3}{*}{5697} & $\mathrm{M}$ & 140 & 6690 & 106 & 25 \\
\hline & & 154 & 6990 & 111 & ND \\
\hline & & 168 & 7290 & 106 & 18 \\
\hline \multirow[t]{3}{*}{6050} & $\mathrm{~F}$ & 141 & 8040 & 117 & 80 \\
\hline & & 155 & 8410 & 117 & 66 \\
\hline & & 168 & 8670 & 111 & 72 \\
\hline \multirow[t]{3}{*}{6052} & $\mathrm{~F}$ & 138 & 6660 & 130 & 61 \\
\hline & & 152 & 6740 & 128 & 51 \\
\hline & & 166 & 7320 & 140 & 79 \\
\hline
\end{tabular}

$\mathrm{ND}$, not determined.

Individual data on body weight and Fe status are given in Table 1. One child was anaemic (haemoglobin $<110 \mathrm{~g} / \mathrm{l}$ ) while none of the infants was Fe deficient (plasma ferritin $<12 \mu \mathrm{g} / \mathrm{l})$. Erythrocyte incorporation data are presented in Table 2. Geometric mean ${ }^{58} \mathrm{Fe}$ incorporation was $7.6 \%$ (range 3.3-13.5\%) from formula given over approximately $24 \mathrm{~h}$ (Protocol A) and 10.6\% (range 6.7-18.6\%) from formula fed on three consecutive days (Protocol B).

Table 2. Erythrocyte incorporation (\% of dose) of ${ }^{58} \mathrm{Fe}$ from infant formula administered over $24 \mathrm{~h}$ (Protocol $\mathrm{A}$ ) or in three equal portions (Protocol B) and of ${ }^{57} \mathrm{Fe}$ given as a reference dose

\begin{tabular}{|c|c|c|c|c|}
\hline \multirow[b]{2}{*}{ Infant } & \multicolumn{2}{|c|}{ Protocol A } & \multicolumn{2}{|c|}{ Protocol B } \\
\hline & $\begin{array}{c}\text { Infant } \\
\text { formula }\end{array}$ & $\begin{array}{l}\text { Reference } \\
\text { dose }\end{array}$ & $\begin{array}{c}\text { Infant } \\
\text { formula }\end{array}$ & $\begin{array}{c}\text { Reference } \\
\text { dose }\end{array}$ \\
\hline 5685 & 8.0 & $23 \cdot 3$ & 6.9 & $22 \cdot 1$ \\
\hline 5941 & 11.8 & $16 \cdot 1$ & $18 \cdot 6$ & $20 \cdot 8$ \\
\hline 5946 & $13 \cdot 3$ & $21 \cdot 6$ & $17 \cdot 0$ & $14 \cdot 1$ \\
\hline 5947 & 13.5 & 27.6 & $10 \cdot 2$ & 20.2 \\
\hline 5949 & 3.4 & $19 \cdot 3$ & 7.4 & $26 \cdot 6$ \\
\hline 5696 & $3 \cdot 3$ & $10 \cdot 8$ & $8 \cdot 6$ & $25 \cdot 2$ \\
\hline 5272 & 4.6 & $20 \cdot 1$ & 14.1 & 32.9 \\
\hline 5697 & $10 \cdot 6$ & 24.0 & $15 \cdot 0$ & 45.4 \\
\hline 6050 & $7 \cdot 3$ & $16 \cdot 8$ & $6 \cdot 7$ & 20.5 \\
\hline 6052 & $8 \cdot 8$ & $27 \cdot 0$ & $9 \cdot 3$ & $22 \cdot 3$ \\
\hline Mean* & $7 \cdot 6$ & $20 \cdot 0$ & $10 \cdot 6$ & 23.9 \\
\hline$+1 S D$ & $12 \cdot 9$ & 26.5 & $15 \cdot 6$ & $32 \cdot 7$ \\
\hline$-1 \mathrm{SD}$ & 4.5 & $15 \cdot 1$ & $7 \cdot 3$ & $17 \cdot 4$ \\
\hline
\end{tabular}

* Geometric mean.
The difference just failed to reach statistical significance $(P$ 0.05). After analysis of covariance, using incorporation of ${ }^{57} \mathrm{Fe}$ from the reference dose as a covariate, the difference was clearly not statistically significant ( $P$ 0 146). Five infants were fed labelled infant formula in the order Protocol A then Protocol B and the other five infants in the order Protocol B then Protocol A. No statistically significant order effect was found $(P$ 0.066). As expected, erythrocyte incorporation of ${ }^{57} \mathrm{Fe}$ from the water solution with added ascorbic acid (reference dose) was higher than incorporation of ${ }^{58} \mathrm{Fe}$ given with infant formula. Geometric mean ${ }^{57} \mathrm{Fe}$ incorporation was $20.0 \%$ (range 10.8-27.6\%) following Protocol A and 23.9\% (range 14.1-45.4\%) following Protocol B. The difference was not statistically significant $(P 0 \cdot 21)$. CVs for the incorporation of ${ }^{57} \mathrm{Fe}$ were 9.4 and $9.9 \%$ and for incorporation of ${ }^{58} \mathrm{Fe}$ 26.4 and $16.2 \%$ for Protocols A and B respectively.

Data on erythrocyte ${ }^{58} \mathrm{Fe}$ incorporation from infant formula corrected for plasma-ferritin and ${ }^{57} \mathrm{Fe}$ incorporation from the reference dose are given in Table 3 . It is evident that neither correction significantly changed the data. The CV changed from 26.4\% (uncorrected; Protocol A) to $21.5 \%$ when corrected for ${ }^{57} \mathrm{Fe}$ incorporation and to $29.8 \%$ when corrected for plasma ferritin values. The CV for Protocol B changed from $16.2 \%$ (uncorrected) to $20.4 \%$ and $22.1 \%$ when corrected for the incorporation of ${ }^{57} \mathrm{Fe}$ and plasma ferritin values, respectively.

No statistically significant correlation $(r 0.079, P 0 \cdot 83)$ was found between the erythrocyte incorporation of ${ }^{57} \mathrm{Fe}$ from reference doses administered during Protocols A and 
Table 3. Corrected values for erythrocyte incorporation (\% of dose) of ${ }^{58} \mathrm{Fe}$ from infant formula (Protocols $\mathrm{A}$ and $\mathrm{B}$ )

(Corrections were made to geometric mean plasma ferritin (46 $\mu \mathrm{g} / \mathrm{l}$ ) and geometric mean erythrocyte incorporation from the reference dose $(20.0 \%$, Protocol A; $23.9 \%$, Protocol B)

\begin{tabular}{|c|c|c|c|c|}
\hline \multirow[b]{3}{*}{ Infant } & \multicolumn{2}{|c|}{ Protocol A } & \multicolumn{2}{|c|}{ Protocol B } \\
\hline & \multicolumn{2}{|c|}{ Correction for } & \multicolumn{2}{|c|}{ Correction for } \\
\hline & $\begin{array}{c}\text { Plasma } \\
\text { ferritin }\end{array}$ & $\begin{array}{l}\text { Reference } \\
\text { dose }\end{array}$ & $\begin{array}{c}\text { Plasma } \\
\text { ferritin }\end{array}$ & $\begin{array}{c}\text { Reference } \\
\text { dose }\end{array}$ \\
\hline 5685 & $7 \cdot 8$ & $6 \cdot 9$ & 7.4 & $7 \cdot 5$ \\
\hline 5941 & $12 \cdot 2$ & 14.7 & $19 \cdot 2$ & 21.4 \\
\hline 5946 & $13 \cdot 7$ & $12 \cdot 3$ & 17.5 & $28 \cdot 8$ \\
\hline 5947 & $7 \cdot 4$ & $9 \cdot 8$ & $5 \cdot 6$ & $12 \cdot 1$ \\
\hline 5949 & $4 \cdot 6$ & 3.5 & $10 \cdot 0$ & $6 \cdot 6$ \\
\hline 5696 & $2 \cdot 0$ & $6 \cdot 1$ & $5 \cdot 2$ & $8 \cdot 2$ \\
\hline 5272 & $7 \cdot 2$ & 4.6 & $22 \cdot 1$ & $10 \cdot 2$ \\
\hline 5697 & 4.9 & $8 \cdot 8$ & $6 \cdot 9$ & 7.9 \\
\hline 6050 & 11.5 & 8.7 & $10 \cdot 5$ & $7 \cdot 8$ \\
\hline 6052 & $12 \cdot 0$ & $6 \cdot 5$ & $12 \cdot 6$ & $10 \cdot 0$ \\
\hline Mean* & $7 \cdot 3$ & 7.5 & $10 \cdot 4$ & $10 \cdot 7$ \\
\hline$+1 S D$ & $13 \cdot 2$ & $11 \cdot 7$ & $17 \cdot 4$ & $17 \cdot 3$ \\
\hline$-1 S D$ & $4 \cdot 0$ & 4.9 & $6 \cdot 2$ & $6 \cdot 6$ \\
\hline
\end{tabular}

* Geometric mean.

B. Neither was erythrocyte incorporation of ${ }^{58} \mathrm{Fe}$ in Protocol A statistically significantly correlated with that in Protocol B ( $r$ 0.60, $P$ 0.067). Within protocols, the relationship between incorporation of ${ }^{58} \mathrm{Fe}$ and ${ }^{57} \mathrm{Fe}$ was weak for Protocol A ( $r$ 0.588, $P$ 0.074) and non-existent for Protocol B $(r$ 0.042, $P$ 0.907). No relationship was found in either protocol between plasma ferritin concentration and erythrocyte incorporation of ${ }^{58} \mathrm{Fe}$ or ${ }^{57} \mathrm{Fe}$.

\section{Discussion}

The results from this study showed that mean $\mathrm{Fe}$ erythrocyte incorporation was about $8-11 \%$ from low-Fe formula when evaluated in healthy, non-Fe deficient infants. Although the difference in erythrocyte incorporation of ${ }^{58} \mathrm{Fe}$ between Protocols A (geometric mean $7.6 \%$ ) and B (geometric mean $10.6 \%$ ) was not statistically

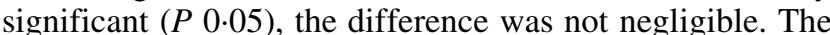
smaller $\mathrm{CV}$ in erythrocyte incorporation of ${ }^{58} \mathrm{Fe}$ during Protocol B can be assume to indicate that day-to-day differences are smoothed out by administration of labelled test meals over $3 \mathrm{~d}$. Erythrocyte incorporation of ${ }^{58} \mathrm{Fe}$ was higher when administered in six equal portions over three consecutive days as compared with ingestion of $1000 \mathrm{~g}$ formula over $24 \mathrm{~h}$. Thus, our data indicate agreement with the earlier observation of higher whole-body $\mathrm{Fe}$ retention from a smaller volume of labelled formula, as compared with a larger volume, in infant rhesus monkeys (Davidson et al. 1990). The adherence to strictly standardised experimental conditions, for example volume of labelled test meals, mode of feeding, etc., is therefore important in studies designed to evaluate the influence of dietary components on $\mathrm{Fe}$ bioavailability or to compare the efficiency of $\mathrm{Fe}$ absorption from different foods.

Comparisons between studies of $\mathrm{Fe}$ bioavailability are further complicated by the influence of $\mathrm{Fe}$ status on $\mathrm{Fe}$ bioavailability. Fe absorption from a reference dose has been established as a useful tool to correct Fe absorption values for differences in $\mathrm{Fe}$ status in adults (Layrisse et al. 1969) and would be an interesting approach also in infants. So far, no information has been published on the usefulness of a reference dose for this purpose in infant studies. However, observations from earlier studies demonstrated statistically significant correlations between ${ }^{58} \mathrm{Fe}$ erythrocyte incorporation from ${ }^{58} \mathrm{Fe}$ administered between meals and plasma ferritin in formula fed (Fomon et al. 1988) and breast-fed infants (Fomon et al. 1995). These data indicate that the administration of a reference dose as a measure of Fe status could be useful also in infant studies. In the present study we therefore included measurements of ${ }^{57} \mathrm{Fe}$ erythrocyte incorporation from a reference dose. Our data demonstrated markedly less inter-individual variation in erythrocyte incorporation for ${ }^{57} \mathrm{Fe}$ given as a reference dose than for ${ }^{58} \mathrm{Fe}$ given with infant formula. However, no statistically significant correlation between erythrocyte incorporation of ${ }^{57} \mathrm{Fe}$ from the reference dose and plasma ferritin could be found ( $P$ 0.83). Furthermore, no statistically significant $\left(\begin{array}{lll}P & 0.21\end{array}\right)$ correlation was found between the incorporation of ${ }^{57} \mathrm{Fe}$ administered on two separate occasions, 2 weeks apart, during which time only minor changes in $\mathrm{Fe}$ status parameters were observed. The lack of correlation between erythrocyte incorporation from the two separate reference doses as well as lack of correlation between plasma ferritin and ${ }^{57} \mathrm{Fe}$ incorporation from the reference dose indicate the limited usefulness of the inclusion of a reference dose in studies of $\mathrm{Fe}$ bioavailability in non-Fe-deficient infants. Nevertheless, using ${ }^{57} \mathrm{Fe}$ incorporation from the reference dose as a covariate, the difference in ${ }^{58} \mathrm{Fe}$ incorporation between the two protocols was diminished to some extent. The use of plasma ferritin as a covariate did not influence the variation in ${ }^{58} \mathrm{Fe}$ incorporation between study protocols.

In this study, Protocol A was chosen to mimic the administration of labelled feeds as used in our previous study with extrinsically-labelled human milk (Davidsson $e t$ al. 1994a). For comparison, a protocol with ingestion of labelled test meals over a period of $3 \mathrm{~d}$ was included (Protocol B). Although comparison of data on Fe bioavailability between separate studies must be made with great caution, it is interesting to note the similar geometric means in erythrocyte incorporation from low-Fe formula in the present study and from extrinsically-labelled human milk (Davidsson et al. 1994a). The geometric mean incorporation of ${ }^{58} \mathrm{Fe}$ from extrinsically-labelled human milk, prepared by the addition of ${ }^{58} \mathrm{Fe}(0.5 \mathrm{mg})$ to human milk (700-1000 g), was $10.6 \%$ (range $3.1-33.7 \%$; erythrocyte incorporation re-calculated from absorption data of Davidsson et al. 1994a).

Due to practical and ethical reasons, no direct comparisons have been made of $\mathrm{Fe}$ bioavailability from human milk and infant formula in infants. As already discussed, comparisons of $\mathrm{Fe}$ bioavailability between studies can only provide limited information. Bioavailability of Fe depends on the presence of enhancers and inhibitors in the diet and, obviously, there are numerous differences in the overall composition of the low-Fe formula used in the present study and the extrinsically-labelled human milk in our 
previous study (Davidsson et al. 1994a). However, it is of importance to note that the low-Fe infant formula used in the present study was a whey-predominant formula with a low content of bovine casein, a relatively low calcium content and a high concentration of ascorbic acid. Bovine casein and calcium are known to inhibit (Hurrell et al. 1989; Hallberg et al. 1991, 1992) and ascorbic acid to enhance (Derman et al. 1980; Stekel et al. 1986; Gillooly et al. 1984; Davidsson et al. 1994b; Fairweather-Tait et al. 1996) Fe bioavailability.

Furthermore, the total $\mathrm{Fe}$ content of test meals is of importance since decreased fractional absorption of $\mathrm{Fe}$ has been demonstrated with increased Fe content of the test meal in adults (Bothwell et al. 1979). In our previous study (Davidsson et al. 1994a) the total Fe content of human milk was increased considerably by the addition of $\mathrm{Fe}$ stable isotopes, resulting in $0 \cdot 6-0 \cdot 7 \mathrm{mg} \mathrm{Fe} / 1000 \mathrm{~g}$. Very little is known about the effect of different $\mathrm{Fe}$ doses on $\mathrm{Fe}$ bioavailability in infants. A recent study reported mean ${ }^{58} \mathrm{Fe}$ incorporation of $4.3 \%$ from a formula with $8 \mathrm{mg} \mathrm{Fe} / \mathrm{l}$ as compared with incorporation of $2.6 \%$ from a formula fortified with $12 \mathrm{mg} \mathrm{Fe} / \mathrm{l}$ (Fomon et al. 1997). It is not known if erythrocyte incorporation could be influenced by small differences in $\mathrm{Fe}$ concentration; i.e., the difference between $0.6 \mathrm{mg} \mathrm{Fe} / \mathrm{kg}$ labelled human milk and $1.4 \mathrm{mg} \mathrm{Fe} /$ $\mathrm{kg}$ of the infant formula used in this study. If indeed such small differences have a significant effect on fractional erythrocyte incorporation, it should have favoured human milk.

It should be noted that erythrocyte incorporation was used as a proxy for Fe bioavailability in the present study, as well as in previous studies by us (Davidsson et al. 1994a; Fomon et al. 1997). This methodology assumes that a large proportion of newly-absorbed $\mathrm{Fe}$ is readily incorporated into erythrocytes. Although some information is available on erythrocyte incorporation of injected Fe in very young infants (Garby et al. 1964) and in low-birth-weight infants (Gorten et al. 1963; Ehrenkranz et al. 1992; Zlotkin et al. 1995), no studies have been reported on erythrocyte incorporation rate of absorbed $\mathrm{Fe}$ in older, term infants. Recently, significant differences between $\mathrm{Fe}$ retention (based on $11 \mathrm{~d}$ faecal collections) and erythrocyte incorporation of ${ }^{58} \mathrm{Fe}$ were reported in term infants (Fomon et al. 2000). Geometric mean retention and erythrocyte incorporation were 26.9 and $5.2 \%$ respectively in nine young infants (20-69 d) and 32.5 and $12.5 \%$ respectively in nine older infants (165-215 d). The authors conclude that infants incorporate far less than $80 \%$ of retained isotope into erythrocytes. Thus, estimating Fe retention based on the assumption that $80-100 \%$ of absorbed $\mathrm{Fe}$ is promptly incorporated into erythrocytes will result in a several-fold underestimate of retention. However, these methodological uncertainties do not invalidate the use of erythrocyte incorporation for the purpose of comparing different diets or when evaluating the impact of dietary composition on erythrocyte incorporation of $\mathrm{Fe}$.

\section{Conclusion}

Fractional erythrocyte incorporation of $\mathrm{Fe}$ from low-Fe infant formula was in the same range as our earlier published data on erythrocyte incorporation of $\mathrm{Fe}$ from human milk extrinsically labelled with ${ }^{58} \mathrm{Fe}$ (Davidsson $e t$ al. 1994a). The methodological evaluations included in this study clearly indicate the importance of using standardised study protocols when evaluating $\mathrm{Fe}$ bioavailability in infants. Corrections of erythrocyte incorporation data based on plasma ferritin or $\mathrm{Fe}$ bioavailability from a reference dose were not found to be useful in the non-Fedeficient infants included in this study.

\section{Acknowledgements}

The authors would like to express their gratitude to all infants and their parents participating in the study and to Mrs Joan Frantz and her colleagues in the Metabolism Ward for excellent collaboration.

\section{References}

Bothwell TH, Charlton RW, Cook JD \& Finch CA (1979) In Iron metabolism in man. Oxford: Blackwell Scientific.

Committee on Nutrition, American Academy of Pediatrics (1999) Iron fortification of infant formulas. Pediatrics 104, 119-123.

Cook JD, Layrisse M \& Finch CA (1969) The measurement of iron absorption. Blood 33, 421-429.

Cook JD, Dassenko SA \& Lynch SR (1991) Assessment of the role of nonheme-iron bioavailability in iron balance. American Journal of Clinical Nutrition 54, 717-722.

Dallman PR (1992) Changing iron needs from birth through adolescence. In Nutritional Anemias, pp. 29-36 [SJ Fomon and S Zlotkin, editors]. New York, NY: Raven Press.

Davidson LA, Litov RE \& Lönnerdal B (1990) Iron retention from lactoferrin-supplemented formulas in infant rhesus monkeys. Pediatric Research 27, 176-180.

Davidsson L, Kastenmayer P, Yuen M, Lönnerdal B \& Hurrell RF (1994a) The influence of lactoferrin on iron absorption from human milk in infants. Pediatric Research 35, 117-124.

Davidsson L, Galan P, Kastenmayer P, Cherouvrier F, Juillerat MA, Hercberg S \& Hurrell RF (1994b) Iron bioavailability studied in infants: the influence of phytic acid and ascorbic acid in infant formulas based on soy isolate. Pediatric Research 36, $816-822$.

Derman DP, Bothwell TH, MacPhail AP, Torrance JD, Bezwoda WR, Charlton RW \& Mayet FGH (1980) Importance of ascorbic acid in the absorption of iron from infant foods. Scandinavian Journal of Haematology 25, 193-201.

Ehrenkranz RA, Gettner PA, Nelli CM, Sherwonit EA, Williams JW, Pearson HA, Ting BTG \& Janghorbani M (1992) Iron absorption and incorporation in red blood cells by very low birth weight infants: studies with the stable isotope ${ }^{58} \mathrm{Fe}$. Journal of Pediatric Gastroenterology and Nutrition 15, 270-278.

Fairweather-Tait S, Fox T, Wharf SG \& Eagles J (1996) The bioavailability of iron in different weaning foods and the enhancing effect of a fruit drink containing ascorbic acid. Pediatric Research 37, 389-394.

Fomon SJ, Janghorbani M, Ting BTG, Ziegler EE, Rogers RR, Nelson SE, Ostedgaard LS \& Edwards BB (1988) Erythrocyte incorporation of ingested 58-iron by infants. Pediatric Research 24, 20-24.

Fomon SJ, Ziegler EE, Nelson SE, Serfass RE \& Frantz JA (1995) Erythrocyte incorporation of iron by 56-day-old infants fed a ${ }^{58} \mathrm{Fe}$-labelled supplement. Pediatric Research 38, 373-378.

Fomon SJ, Ziegler EE, Serfass RE, Nelson SE \& Frantz JA (1997) Erythrocyte incorporation of iron is similar in infants fed 
formulas fortified with $12 \mathrm{mg} / \mathrm{L}$ or $8 \mathrm{mg} / \mathrm{L}$ of iron. Journal of Nutrition 127, 83-88.

Fomon SJ, Ziegler EE, Serfass RE, Nelson SE, Rogers RR \& Frantz JA (2000) Less than $80 \%$ of absorbed iron is promptly incorporated into erythrocytes of infants. Journal of Nutrition 130, 45-52.

Food and Drug Administration (1985) Rules and regulations. Nutrient requirements for infant formulas (21 CFR Part 107). Federal Register 50, 45106-45108.

Garby L, Sjölin S \& Vuille J-C (1964) Studies on erythro-kinetics in infancy. IV. The long-term behaviour of radioiron in circulating foetal and adult haemoglobin, and its faecal excretion. Acta Paediatrica 53, 33-41.

Gillooly M, Torrance JD, Bothwell TH, MacPhail AP, Derman D, Mills W \& Mayet F (1984) The relative effect of ascorbic acid on iron absorption from soy-based and milk-based infant formulas. American Journal of Clinical Nutrition 40, 522-527.

Gorten MK, Hepner R \& Workman JB (1963) Iron metabolism in premature infants. I. Absorption and utilization of iron as measured by isotope studies. Journal of Pediatrics 63, 10631071.

Hallberg L, Brune M, Erlandsson M, Sandberg A-S \& RossanderHulthén L (1991) Calcium: effect of different amounts on nonheme- and heme-iron absorption in humans. American Journal of Clinical Nutrition 53, 112-119.

Hallberg L, Rossander-Hulthén L, Brune M \& Gleerup A (1992) Bioavailability in man of iron in human milk and cow's milk in relation to their calcium contents. Pediatric Research 31, 524527.

Hurrell RF, Lynch SR, Trinidad TP, Dassenko SA \& Cook JD (1989) Iron absorption in humans as influenced by bovine milk proteins. American Journal of Clinical Nutrition 49, 546-552.

Innis SM, Nelson CM, Wadsworth LD, MacLaren IA \& Lwanga D
(1997) Incidence of iron-deficiency anemia and depleted iron stores among nine-month-old infants in Vancouver, Canada. Canadian Journal of Public Health 88, 80-84.

Kastenmayer P, Davidsson L, Galan P, Cherouvrier F, Hercberg S \& Hurrell RF (1994) A double stable isotope technique for measuring iron absorption in infants. British Journal of Nutrition 71, 411-424.

Layrisse M, Cook JD, Martinez C, Roche M, Kuhn IN, Walker RD \& Finch CA (1969) Food iron absorption: A comparison of vegetable and animal foods. Blood 33, 430-433.

Lönnerdal B (1984) Iron and breast milk. In Iron Nutrition in Infancy and Childhood. Nestlé Nutrition Workshop Series volume 4, pp. 95-114 [A Stekel, editor]. New York, NY: Raven Press.

Looker AC, Dallman P, Caroll MD, Gunter EW \& Johnson CL (1997) Prevalence of iron deficiency in the United States. JAMA 277, 973-976.

Siimes MA, Vuori E \& Kuitunen P (1979) Breast milk iron: a declining concentration during the course of lactation. Acta Paediatrica Scandinavica 68, 29-31.

Stekel A, Olivares M, Pizarro F, Chadud P, Lopez I \& Amar M (1986) Absorption of fortification iron from milk formulas in infants. American Journal of Clinical Nutrition 43, 917-922.

Zlotkin SH, Lay DM, Kjarsgaard J \& Longley T (1995) Determination of iron absorption using erythrocyte iron incorporation of two stable isotopes of iron $\left({ }^{57} \mathrm{Fe}\right.$ and $\left.{ }^{58} \mathrm{Fe}\right)$ in very low birthweight premature infants. Journal of Pediatric Gastroenterology and Nutrition 21, 190-199.

Van de Casteele C \& Block CB (1993) Methodology in trace element determination. In Modern Methods for Trace Element Determination, pp. 66-68. Chichester: John Wiley \& Sons. 